\title{
Congenital aplasia of the scaphoid bone
}

\author{
Hakan Çetin (1), Ali Bülent Baz (1), Ömer Faruk Kılıçaslan (D), Aliekber Yapar(1) \\ Department of Orthopedics and Traumatology, Antalya Training and Research Hospital, Antalya, Turkey
}

Congenital aplasia of the scaphoid bone without thumb or radial hypoplasia is a rare condition. Scaphoid hypoplasia and aplasia has been defined with syndromes such as radial hemimelia, absence of thumb, vertebral defects, anal atresia, cardiac anomalies, tracheoesophageal fistula, renal anomalies, and limb abnormalities (VACTERL), Holt-Oram syndrome (heart defects and upper extremity anomalies), and thrombocytopenia-radius anomalies (TAR). Scaphoid anomalies are often seen associated with absence of thumb or radius. In the literature, there are seven case reports with isolated scaphoid aplasia without other congenital abnormalities, but none of them are current. ${ }^{[1-7]}$ Herein, we present a very rare case diagnosed in the pediatric age group with hypoplasia of the biceps brachii ipsilateral to scaphoid aplasia.

\section{CASE REPORT}

A 12-year-old male patient was applied to the orthopedics and traumatology outpatient clinic

\section{Received: December 29, 2021}

Accepted: January 16, 2022

Published online: February 10, 2022

Correspondence: Aliekber Yapar, MD. Antalya Eğitim ve Araştırma Hastanesi Ortopedi ve Travmatoloji Kliniği,

07100 Muratpaşa, Antalya, Türkiye.

E-mail: aliekberyapar@hotmail.com

Doi: 10.52312/jdrscr.2022.51

Citation: Çetin H, Baz AB, Kılıçaslan ÖF, Yapar A. Congenital aplasia of the scaphoid bone. Jt Dis Relat Surg Case Rep 2022;1(2):47-50.

(O2022 All right reserved by the Turkish Joint Diseases Foundation

This is an open access article under the terms of the Creative Commons Attribution-NonCommercial License, which permits use, distribution and reproduction in any medium, provided the original work is properly cited and is not used for commercial purposes (http://creativecommons. org/licenses/by-nc/4.0/).

https://www.casereportsjointdrs.org

\section{ABSTRACT}

Congenital aplasia of the scaphoid bone without thumb or radial hypoplasia is a rare condition. In the literature, there are seven case reports of congenital scaphoid aplasia without other congenital abnormalities, but none of them are current. Scaphoid hypoplasia and aplasia have been defined with syndromes such as radial hemimelia, absence of thumb, vertebral defects, anal atresia, cardiac anomalies, tracheoesophageal fistula, renal anomalies, and limb abnormalities (VACTERL), Holt-Oram syndrome (heart defects and upper extremity anomalies), and thrombocytopenia-radius anomalies (TAR). This is a very rare case diagnosed in the pediatric age group with hypoplasia of the biceps brachii ipsilateral to scaphoid aplasia. Herein, a 12 -year-old boy with unilateral scaphoid agenesis is presented, and its clinical and imaging findings as well as the treatment are discussed.

Keywords: Aplasia, congenital, scaphoid.

12 months ago with right wrist weakness and limited range of movement. After the physical examination and radiographs of the patient, he was diagnosed with scaphoid agenesis. There were no features in the history, no additional systemic disease, no syndromic facial appearance, and the patient's intelligence was normal.

The right wrist differed from the left side in terms of thenar atrophy, palmar creases, and distal wrist crease (Figure 1). On the right side, hypoplasia of the biceps brachii was seen (Figure 2). There was no tenderness and pain in the first carpometacarpal and radiocarpal joints on palpation. Right radial pulse was non-palpable, right ulnar pulse was palpable, and there was a delay on the right in Allen's test. Wrist instability tests were negative. There was no neurological deficit. Bilateral upper extremities were of equal length. Thumb and other finger joint ranges of motion were normal and right wrist movements were diminished, particularly in dorsiflexion. The joint range of motion measurement 

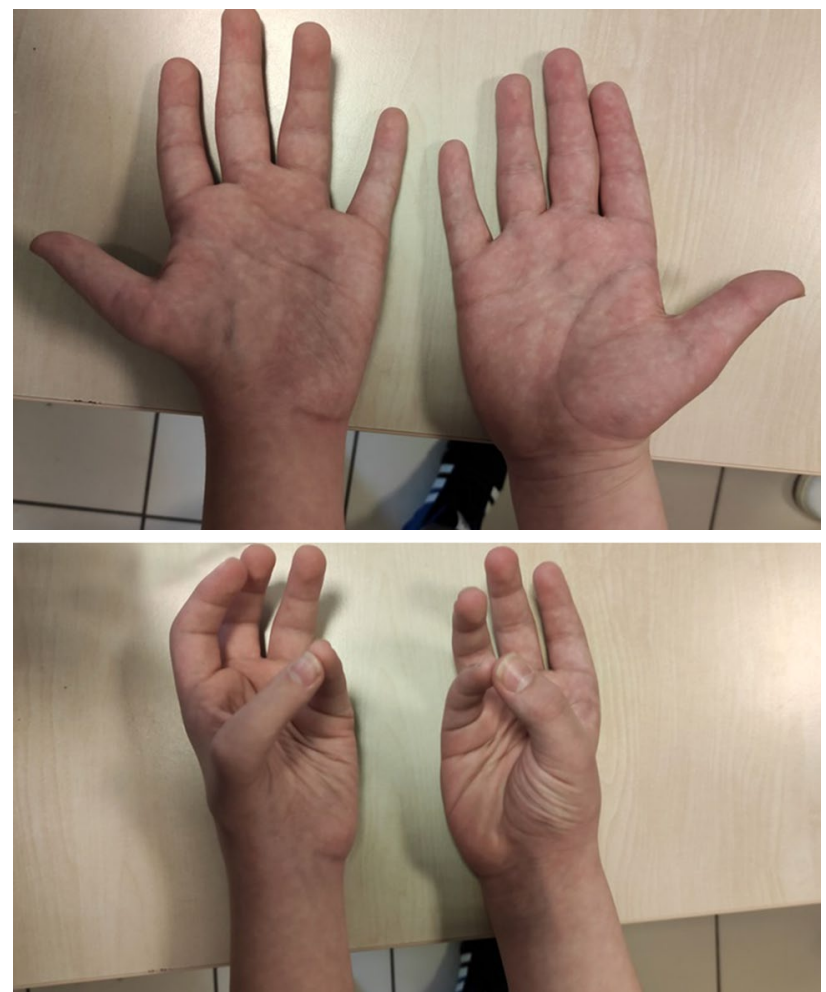

Figure 1. Morphological images of the hands.

values and grip strength of the patient are presented in Table 1.

In the radiographic examination, there was no scaphoid bone on the right side, the alignment and morphology of the other carpal bones were normal (Figure 3). The carpal bones on the left had a normal appearance. The trapezium had a dysplastic appearance on the right, lost its pyramidal feature, and its height was measured as $10.6 \mathrm{~mm}$, on the left, it was measured as $14.8 \mathrm{~mm}$. The right radius styloid had a hypoplastic appearance, and the distal radioulnar joint was normal. Carpal height ratio was measured as 0.36 on the right wrist and 0.59 on the left, $38 \%$ less on the side without scaphoid. There were no degenerative changes in the intercarpal and radiocarpal joints. Magnetic resonance imaging (MRI) confirmed the absence of scaphoid bone in the right wrist. Other carpal bones were in normal configuration. The morphology and signals of other carpal bones forming the wrist were normal. No pathology was detected in the periarticular tissues. Computed tomography (CT) showed that the scaphoid bone socket was smaller than expected and there was a millimetric ossific bone fragment on the volar side. It was thought that the ratio of the radius distal articular surface to the ulna articular surface may
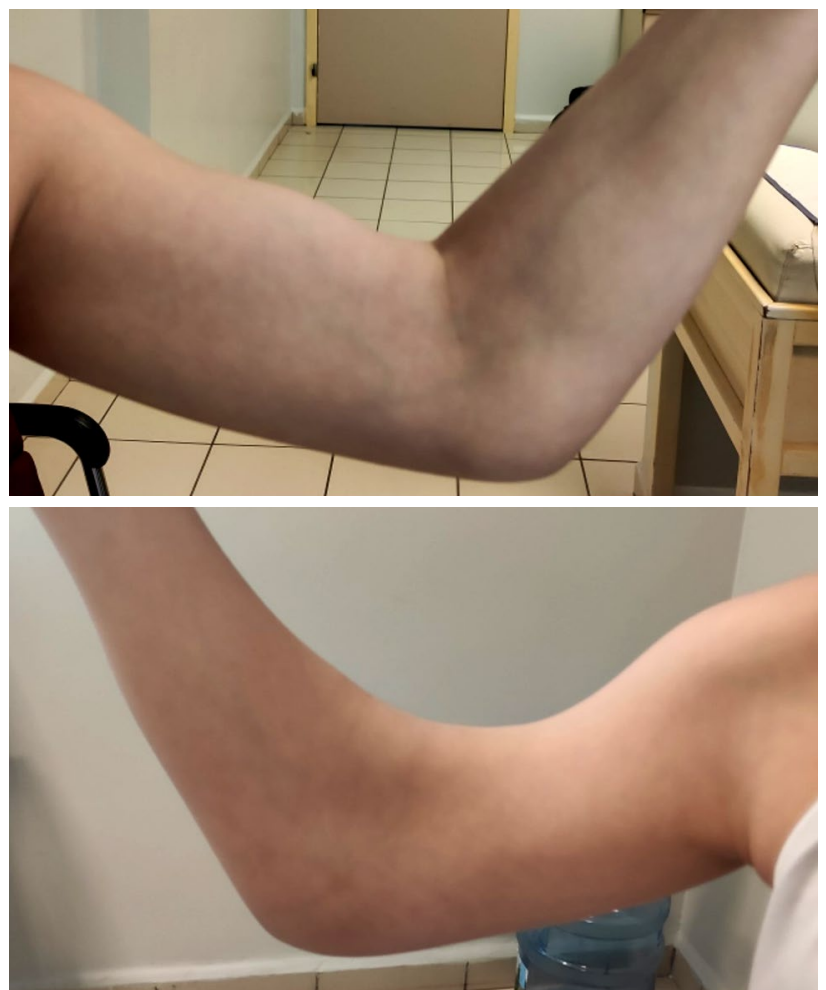

Figure 2. Hypoplasia of the biceps brachii.

have decreased. No significant deterioration was observed in the axis (Figure 4). On electromyography, partial dysfunction of the motor and sensory branches of the median nerve was reported, compatible with neuropathy. Brachial plexus MRI was performed and no pathology was detected. Surgical treatment was not planned for the patient with these findings. The patient is still under follow-up on a regular basis in the orthopedic outpatient setting.

The parents were informed that data from the case would be submitted for publication and gave their consent.

TABLE 1

Joint range of motion values and grip strength measurement

\begin{tabular}{lcc}
\hline & Right & Left \\
\hline Range of motion & 55 & 75 \\
Flexion & 10 & 65 \\
Extension & 10 & 30 \\
Ulnar deviation & 15 & 20 \\
Radial deviation & & \\
Grip strength (kg) & 1.5 & 7.3 \\
Strength at Jamar & 10.6 & 25.2 \\
K-Pinch &
\end{tabular}



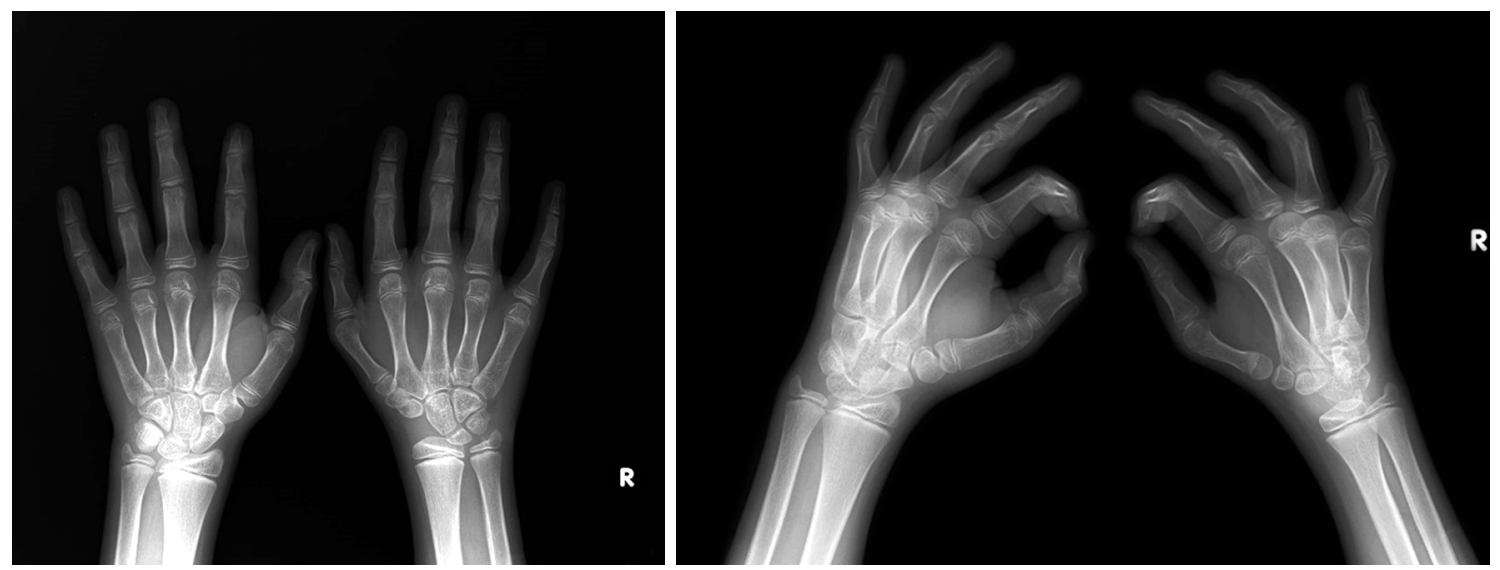

Figure 3. X-ray images of both wrists.
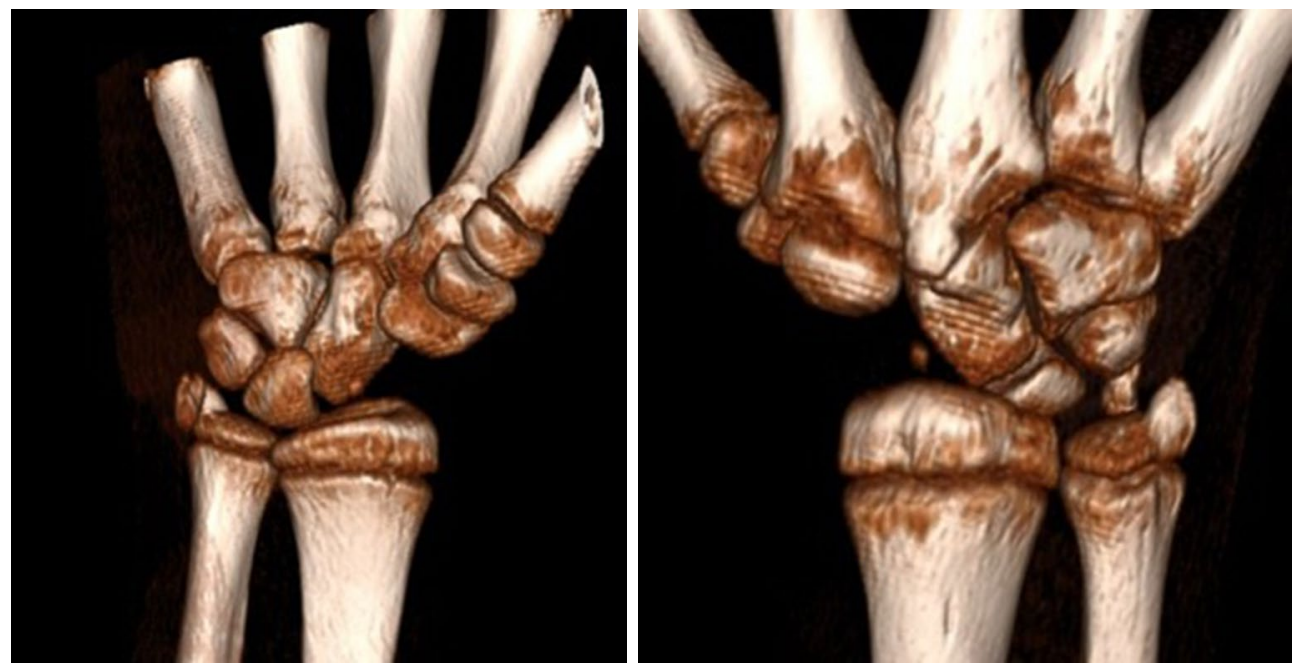

Figure 4. Three-dimensional computed tomography images of the wrists.

\section{DISCUSSION}

Scaphoid aplasia is rare. In the literature, there are seven cases with isolated scaphoid aplasia (Table 2). ${ }^{[1-7]}$ The most recent publication on this subject is dated 2012, and our case was written to contribute to the current literature. In addition, our case is the youngest case in age among the cases published on this subject.

Davison $^{[8]}$ created a classification of six different types of scaphoid hypoplasia, ranging from mild hypoplasia to complex hypoplasia and aplasia affecting the forearm and fingers. He concluded that the defect occurred as a result of embryological damage affecting the skeleton in the proximal and distal sequence. However, he did not explain the possibility of the absence of the scaphoid associated with the normal thumb. In the Davison's classification, the complete absence of the scaphoid has always been associated with severe hypoplasia and aplasia of the thumb. Our case is not similar to the Davison classification, as there was no associated longitudinal disorder.

In the classifications published after $\mathrm{O}^{\prime}$ Rahilly, ${ }^{[9]}$ the concept of intercalary deficiency has been largely abandoned; therefore, this classification that includes intercalary radial hemimelia is the only classification consisting of congenital malformation of our patient. ${ }^{[7,9]}$

Radial styloid hypoplasia of our patient was attributed to the absence of scaphoid contact, and thenar atrophy was attributed to median nerve entrapment neuropathy. In the literature, carpal tunnel syndrome (CTS) was seen in patients with isolated scaphoid agenesis; however, since all of these 


\section{TABLE 2}

Review of the literature about aplasia of the scaphoid bone

\begin{tabular}{|c|c|c|c|c|}
\hline Author & Year & Age/Sex & Clinical features & Article title \\
\hline Papanikolaou and Haddadin ${ }^{[2]}$ & 1972 & $22 / \mathrm{M}$ & $\begin{array}{l}\text { Pain in the left wrist as a result of } \\
\text { a fall on the outstretched hand. }\end{array}$ & $\begin{array}{l}\text { Congenital absence of carpal } \\
\text { scaphoid. }\end{array}$ \\
\hline Srivastava and Kochhar ${ }^{[4]}$ & 1972 & $26 / M$ & $\begin{array}{l}\text { Pain in wrist at the limits o of } \\
\text { motion. }\end{array}$ & $\begin{array}{l}\text { Congenital absence of the carpal } \\
\text { scaphoid }\end{array}$ \\
\hline Kuz and Smith ${ }^{[6]}$ & 1997 & $18 / \mathrm{M}$ & $\begin{array}{l}\text { Pain after a history of a right wrist } \\
\text { sprain }\end{array}$ & $\begin{array}{l}\text { Congenital absence of the } \\
\text { scaphoid without other congenital } \\
\text { abnormality: a case report. }\end{array}$ \\
\hline Patankar ${ }^{[3]}$ & 1998 & $28 / \mathrm{M}$ & $\begin{array}{l}\text { Pain, swelling and stiffness of the } \\
\text { left wrist following an injury }\end{array}$ & $\begin{array}{l}\text { Bilateral congenital aplasia of the } \\
\text { scaphoid }\end{array}$ \\
\hline Chamay $^{[1]}$ & 2001 & $66 / M$ & $\begin{array}{l}\text { Pain localized at the base of the } \\
\text { thumb }\end{array}$ & $\begin{array}{l}\text { Unilateral congenital aplasia of } \\
\text { the scaphoid and dysplasia of the } \\
\text { trapezium: a case report }\end{array}$ \\
\hline Panciera and Le Viet ${ }^{[7]}$ & 2008 & $45 / \mathrm{M}$ & $\begin{array}{l}\text { Pain, swelling, and stiffness of } \\
\text { both wrists without any history of } \\
\text { injury or other joint complaints. }\end{array}$ & $\begin{array}{l}\text { Intercarpal degenerative arthritis in } \\
\text { adulthood as a late consequence } \\
\text { of unilateral congenital aplasia of } \\
\text { scaphoid: a case report }\end{array}$ \\
\hline Gómez Fernández et al. ${ }^{[5]}$ & 2012 & $49 / M$ & $\begin{array}{l}\text { Mild pain in the wrist for about } \\
20 \text { years. }\end{array}$ & $\begin{array}{l}\text { Unilateral congenital absence of } \\
\text { the carpal scaphoid associated } \\
\text { with dysplasia of the capitate }\end{array}$ \\
\hline
\end{tabular}

patients were elderly patients, it was assumed that scaphoid agenesis did not cause CTS. As a defense, the absence of CTS was shown in a 15-year-old young patient reported by Radford ${ }^{[10]}$ However, our patient had CTS despite his young age. This raises the question of whether scaphoid agenesis could cause CTS. In addition, carpal collapse was observed in all cases reported in the literature, and our case is no exception.

In conclusion, our patient did not have pain in joint movements, but his right wrist movements were limited compared to the left side. There was no sign of carpal instability in the wrist. Although the congenital aplasia of scaphoid bone is not the risk factor for carpal instability, there is no study comparing congenital scaphoid aplasia and acquired scaphoid excision in terms of instability.

\section{Declaration of conflicting interests}

The authors declared no conflicts of interest with respect to the authorship and/or publication of this article.

\section{Funding}

The authors received no financial support for the research and/or authorship of this article.

\section{REFERENCES}

1. Chamay A. Unilateral congenital aplasia of the scaphoid and dysplasia of the trapezium (a case report). Chir Main 2001;20:466-70.

2. Papanikolaou P, Haddadin MA. Congenital absence of carpal scaphoid. Br Med J 1972;2:292.

3. Patankar H. Bilateral congenital aplasia of the scaphoid. J Hand Surg Br 1998;23:817-9.

4. Srivastava KK, Kochhar VL. Congenital absence of the carpal scaphoid. A case report. J Bone Joint Surg [Am] 1972;54:1782.

5. Gómez Fernández JM, Méndez López JM, Caracuel Redondo F. Unilateral congenital absence of the carpal scaphoid associated with dysplasia of the capitate. Presentation of a case. Rev Esp Cir Ortop Traumatol 2012;56:156-9.

6. Kuz JE, Smith JM. Congenital absence of the scaphoid without other congenital abnormality: A case report. J Hand Surg Am 1997;22:489-91.

7. Panciera P, Le Viet D. Intercarpal degenerative arthritis in adulthood as a late consequence of unilateral congenital aplasia of the scaphoid: A case report. J Hand Surg Am 2008;33:213-6.

8. Davison EP. Congenital hypoplasia of the carpal scaphoid bone. J Bone Joint Surg [Br] 1962;44:816-27.

9. O'Rahilly R. A survey of carpal and tarsal anomalies. J Bone Joint Surg [Am] 1953;35-A:626-42.

10. Radford PJ, Matthewson MH. Hypoplastic scaphoid--an unusual cause of carpal tunnel syndrome. J Hand Surg Br 1987;12:236-8. 